\title{
Analysis of Selection Criteria of Dental Patients for General Anaesthesia and Conscious Sedation
}

\author{
Kader Cesur Aydin ${ }^{1}$ (D), Oguzhan Demirel ${ }^{2}$ (D) \\ ${ }^{1}$ Istanbul Medipol University, Faculty of Dentistry, Department of Dentomaxillofacial Radiology, Istanbul, Turkey. \\ ${ }^{2}$ Bahcesehir University, Faculty of Dentistry, Department of Dentomaxillofacial Radiology, Istanbul, Turkey.
}

Correspondence Author: Kader Cesur Aydin

E-mail: kadercesur@yahoo.com

Received: $11.09 .2019 \quad$ Accepted: 07.03.2020

\begin{abstract}
Objective: The term general anaesthesia refers to a state of unconsciousness under control using pharmacological or non pharmacological agents in which patient reflexes are compeletely or partially lost. Concious sedation is a drug-induced state in which the conscious patient is rendered free of fear, anxiety, and apprehension while remaining comfortably relaxed. Both of these methods are used for various reasons in dental clinics for many years and their use in dentistry practice is increasing. Aim of this study is to quantify the number and demographic data of patients that received a dental general anaesthesia (DGA) or conscious sedation (CS) following referral from a general dental practice. Study also aimed to determine the reasons of referral and dental treatment modalities performed during the sessions. Methods: This study includes patient records who had undergone dental general anaesthesia and conscious sedation in Medipol University Dental Hospital General Anaesthesia Clinic. Data were collected from records of the University Dental Hospital. The collected information included gender, age, type of DGA/ CS, reason for DGA, treatment modalities as tooth extraction, restorative, endodontics, periodontics and pedodontics. Results: 896 patients were referred for DGA/CS during the two-year period. The mean age was 15.5 years and $27.3 \%$ were underaged children. The most common reason for DGA was dental anxiety (46.5\%). $79.4 \%$ of patientd received DGA, while only $20.6 \%$ received CS. The highest mean in treatments is for decidious pulp capping (4.57) followed by decidious pulp amputation (3.57).
\end{abstract}

Conclusion: Majority of the patients receiving DGA/CS are formed by dental anxiety patients. Also, the rate of underaged children were very high (27.3\%).

Keywords: Dentistry, General Anaesthesia, Conscious Sedation, Pediatric Dentistry, Dental Anxiety

\section{INTRODUCTION}

When behaviour management techniques are inadequate for patients with special needs, general anaesthesia and conscious sedation may take a role for these patients' dental treatments. Patients with dental anxiety, intellectual disability, dementia, physical limitations, behavioural disorders and chronic systemic conditions can be included into the group called 'patients with special needs' (1). Although treatment of pediatric patients may be held out without using any pharmacological agents, incorporation with some patients may require sedation and general anaesthesia $(2,3)$.

The term general anaesthesia refers to a state of unconsciousness under control using pharmacological agents. Patient reflexes are compeletely or partially lost including airway control, response to physical or verbal contact is lost (4). In a study conducted by Nunn et al, it is described that 340 patients with varying ages had undergone general anaesthesia for their dental treatments between 1983 to 1993 . Also, review made in the same study pointed out patient quantities in previous researches between 80 and 4000 in variable time periods (5). In 1984, Bennet defined the conscious sedation term as 'drug-induced state in which the conscious patient is rendered free of fear, anxiety, and apprehension while remaining comfortably relaxed' and explained this method is not a method of pain control (6). Pharmacological agents provide the depression of consciousness level, but complete loss is prevented and patient's airway control ability maintains. Patient's response to physical stimulation and verbal contact continues $(7,8)$. In a study conducted by Varpio and Wellfelt included 146 children with dental phobia; while $48 \%$ of children were treated with conventional techniques after been trained by 'tell-show-do' method, $25 \%$ were treated with conscious sedation and $27 \%$ with general anaesthesia (9). Differentiation of conscious sedation applied in dental clinics must be seperated from those made by general anaesthetists made in surgical environments where every kind of patient 
monitoring agents are available. During sedation in dental clinics, patient communication must be maintained (10).

Regarding the benefits and risks of general anesthesia and conscious sedation; complex criteria are included for case and method selection. These criteria included patient anamnesis and evaluation by a dentomaxillofacial radiologist, evaluation of the dental operator, availability of the treatment plan during the selected method and lastly evaluation of the patient by the general anesthesician and planning the protocol.

For obtaining maximum treatment plan goals, patients were all administered for specialist dental operators, tried to comfort and convince for local anesthesia treatments. It is demonstrated that comprehensive discussion of the anesthesia techniques and the specialist reasoning may alter patients' attitude towards anesthesia selection (11).

The purpose of this study is to evaluate a group of dental patients that has undergone dental general anaesthesia (DGA) or conscious sedation (CS) in aspect of clinical necessities such as younger age, mental retardation, surgical necessities, gagging reflex or patient choice due to dental anxiety.

\section{METHODS}

\subsection{Study Design}

This study is held out in Medipol University, School of Dentistry. Data for the study cohort was collected retrospectively via general anesthesia electronic records. Total of 896 patients were analysed (425 female, 471 male) who received either conscious sedation or general anesthesia for their dental treatments. Patients were evaluated by age groups as child (age under 12) or adult (above age 12). Gender, reason of anesthesia and type of anesthesia are evaluated in age groups. Number and ratio of the operated treatments were also determined.

Because this study was a retrospective research based on data collection and informed consents of all patients were taken (which declares that patient information can be used for scientific research); no ethical regulation was required.

\subsection{Statistical analysis}

During evaluation of the cohort data, IBM SPSS Statistics 22 (IBM SPSS, Turkey) program was used for the statistical analysis. Correlation of data for normal distribution was determined by ShapiroWilks test. Mann Whitney $U$ test was used for mean, standard deviation and frequency anlyses. Chi - square test, Fisher Freeman Halton test and Continuity (Yates) Correction was used for determination of the comparison of qualitative data. Statistical significance was determined as $\mathrm{p}<0.05$.

\section{RESULTS}

This study demographics included 896 patients (425 female, 471 male) treated under general anaesthesia or conscious sedation. Mean age and standard deviation of the study group was $15,54 \pm 16,63$ and female / male percentage was $47,4 \%$ to $52,6 \% .67 \%$ of the study group were child patients (under age 12). Table 1 demonstrates the reasons for application to anaesthesia clinic and the technics used for the operation. It can be concluded that the most common cause for DGA/ CS selection in this study group is dental anxiety $(46,5 \%)$, followed by underaged children $(27,3 \%)$.

Table 1. Reasons for application to anaesthesia clinic and selected anesthesia types for the operations.

\begin{tabular}{|l|l|c|c|}
\hline \multirow{4}{*}{$\begin{array}{l}\text { Reasons for } \\
\text { anaesthesia }\end{array}$} & Underaged child & 245 & 27,3 \\
\cline { 2 - 4 } & Patient with special needs & 127 & 14,1 \\
& Mental retardation & 57 & 6,4 \\
& Cerebral palsy & 10 & 1,1 \\
& Autism & 27 & 3 \\
& Down syndrome & 24 & 2,7 \\
& Visual/ hearing impaired & 9 & 1 \\
\cline { 2 - 4 } & Gagging reflex & 28 & 3,1 \\
\cline { 2 - 4 } & Surgical necessity & 79 & 8,8 \\
\cline { 2 - 4 } & Anxiety & 417 & 46,5 \\
\hline Anesthesia type & General anaesthesia & 711 & 79,4 \\
\cline { 2 - 4 } & Sedation & 185 & 20,6 \\
\hline
\end{tabular}

No statistical significance is found among genders for anaesthesia reason, anaesthesia type and distribution of children with special needs ( $p>0.05$ ) (Table 2).

Table 2. Distribution of anesthesia reason and type in children aged $\leq 12$ among genders.

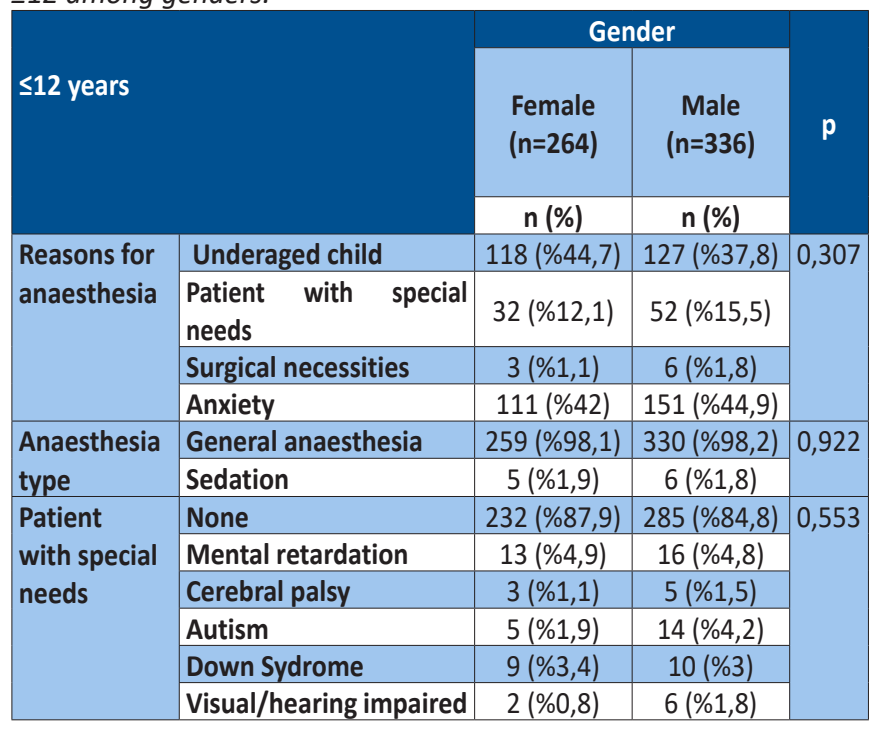

Chi-square test $p<0.01$ 
Statistically significant differences were found in patients over 12 years old. In terms of reasons for general anaesthesia; anxiety was more frequent in females $(p<0.01)$, while gagging reflex and surgical operation neccessities were more frequent in male patients $(p<0.01)$. General properties of patients above 12 years old can be seen in Table 3. Chi-square test results reveal that female patients have statistically significant anxiety rates than man $(p<0.01)$. Applied anesthesia type does not have significance in relation to gender.

Table 3. Distribution of anesthesia reason and type in children aged $>12$ among genders

\begin{tabular}{|c|c|c|c|c|}
\hline \multicolumn{2}{|l|}{$>12$ age } & \multicolumn{2}{|c|}{ Gender } & \multirow[t]{3}{*}{$p$} \\
\hline & & $\begin{array}{l}\text { Female } \\
(n=161)\end{array}$ & $\begin{array}{c}\text { Male } \\
(n=135)\end{array}$ & \\
\hline & & n (\%) & n (\%) & \\
\hline \multirow{5}{*}{$\begin{array}{l}\text { Reasons for } \\
\text { anesthesia }\end{array}$} & Underaged Child & $2(\% 1,2)$ & $0(\% 0)$ & \multirow[t]{5}{*}{$0,001 * *$} \\
\hline & $\begin{array}{l}\text { Patient with } \\
\text { special needs }\end{array}$ & $22(\% 13,7)$ & $24(\% 17,8)$ & \\
\hline & Gagging reflex & $6(\% 3,7)$ & $22(\% 16,3)$ & \\
\hline & $\begin{array}{l}\text { Surgical } \\
\text { necessities }\end{array}$ & $32(\% 19,9)$ & $37(\% 27,4)$ & \\
\hline & Anxiety & $99(\% 61,5)$ & $52(\% 38,5)$ & \\
\hline \multirow[t]{2}{*}{$\begin{array}{l}\text { Anaesthesia } \\
\text { type }\end{array}$} & $\begin{array}{l}\text { General } \\
\text { anaesthesia }\end{array}$ & $65(\% 40,4)$ & $57(\% 42,2)$ & \multirow[t]{2}{*}{0,747} \\
\hline & Sedation & $96(\% 59,6)$ & $78(\% 57,8)$ & \\
\hline \multirow{6}{*}{$\begin{array}{l}\text { Patient } \\
\text { with special } \\
\text { needs }\end{array}$} & None & $141(\% 87,6)$ & $113(\% 83,7)$ & \multirow[t]{6}{*}{0,219} \\
\hline & $\begin{array}{l}\text { Mental } \\
\text { retardation }\end{array}$ & $14(\% 8,7)$ & $11(\% 8,1)$ & \\
\hline & Cerebral palsy & $2(\% 1,2)$ & $0(\% 0)$ & \\
\hline & Autism & $2(\% 1,2)$ & $6(\% 4,4)$ & \\
\hline & Down Syndrome & $1(\% 0,6)$ & $4(\% 3)$ & \\
\hline & $\begin{array}{l}\text { Hearing/ Visual } \\
\text { Impaired }\end{array}$ & $1(\% 0,6)$ & $1(\% 0,7)$ & \\
\hline
\end{tabular}

Chi-square Test ${ }^{* *} p<0.01$

Table 4 and 5 demonstrates the gender distribution of dental operations. No statistically significant difference was observed among genders in patients below 12 years with regard to dental treatments $(p>0.05)$; on the other hand females had higher rate for permanent teeth extractions $(p<0.01)$, subgingival curretage and periodontal flap surgeries $(p<0.05)$.
Table 4. List of dental operations and their relationship between genders in patients aged below 12 years old

\begin{tabular}{|c|c|c|c|}
\hline \multirow{3}{*}{$\leq 12$ years } & \multicolumn{2}{|c|}{ Gender } & \multirow[t]{3}{*}{$1 p$} \\
\hline & $\begin{array}{l}\text { Female } \\
(n=264)\end{array}$ & $\begin{array}{l}\text { Male } \\
(n=336)\end{array}$ & \\
\hline & Mean $\pm S D$ & Mean $\pm S D$ & \\
\hline Endodontic treatment & $4,99 \pm 3,00$ & $5,28 \pm 3,23$ & 0,364 \\
\hline $\begin{array}{l}\text { Decidous tooth } \\
\text { extraction }\end{array}$ & $2,09 \pm 2,42$ & $2,19 \pm 2,39$ & 0,362 \\
\hline $\begin{array}{l}\text { Permanent tooth } \\
\text { extraction }\end{array}$ & $0,11 \pm 0,50$ & $0,15 \pm 0,56$ & 0,254 \\
\hline \multirow[t]{2}{*}{ Restorative treatment } & $5,56 \pm 3,61$ & $5,89 \pm 3,65$ & 0,299 \\
\hline & $n(\%)$ & $n(\%)$ & $2 p$ \\
\hline Surgery & $4(\% 1,5)$ & $12(\% 3,6)$ & 0,195 \\
\hline Detartrage & $8(\% 3)$ & $14(\% 4,2)$ & 0,606 \\
\hline Curretage & $1(\% 0,4)$ & $0(\% 0)$ & 0,440 \\
\hline Flap surgery & $1(\% 0,4)$ & $1(\% 0,3)$ & 1,000 \\
\hline
\end{tabular}

1: Mann Whitney $U$ Test

2: Continuity (Yates)Correction and Fisher's Exact Test

Table 5. List of dental operations and their relationship between genders in patients aged above 12 years old.

\begin{tabular}{|c|c|c|c|}
\hline$>12$ years & Gender & & $1 p$ \\
\hline & $\begin{array}{l}\text { nale } \\
161)\end{array}$ & $\begin{array}{c}\text { Male } \\
(n=135)\end{array}$ & \\
\hline Mea & $\mathrm{n} \pm \mathrm{SD}$ & Mean $\pm S D$ & \\
\hline Endodontic treatment & $0,34 \pm 0,94$ & $0,58 \pm 1,41$ & 0,128 \\
\hline Decidous tooth extraction & $0,03 \pm 0,26$ & $0,11 \pm 0,76$ & 0,526 \\
\hline Permanent tooth extraction & $1,75 \pm 3,36$ & $1,16 \pm 2,62$ & $0,033^{*}$ \\
\hline Implant surgery & $0,45 \pm 1,37$ & $0,87 \pm 2,49$ & 0,184 \\
\hline Restorative treatment & $1,14 \pm 2,63$ & $1,43 \pm 2,74$ & 0,123 \\
\hline & $n(\%)$ & $n(\%)$ & $2 p$ \\
\hline Surgery & $36(\% 22,4)$ & $40(\% 29,6)$ & 0,196 \\
\hline Lefort surgery & $7(\% 4,3)$ & $6(\% 4,4)$ & 1,000 \\
\hline Detartrage & $45(\% 28)$ & $34(\% 25,2)$ & 0,686 \\
\hline Curretage & $11(\% 6,8)$ & $0(\% 0)$ & $0,005 * *$ \\
\hline Flap surgery & $8(\% 5)$ & $1(\% 0,7)$ & $0,043 *$ \\
\hline Prosthetic treatment & $11(\% 6,8)$ & $10(\% 7,4)$ & 1,000 \\
\hline
\end{tabular}

Table 6 demonstrates the distribution of dental treatments and their relationships between age groups. Restorative treatment modalities showed significant differences between age groups. While pulp capping operations of decidous teeth and fissure restorations in patients below 12 years age were more frequent than patients above 12 years old $(p<0.01)$; permanent tooth pulp cappings and amalgam restorations were more common in patients above 12 years old $(p<0.01)$. 
No statistically significant differences were found in terms of tooth extractions between age groups $(p>0.01)$.

With regard to endodontic treatments, statistical significance was evident between age groups. Decidous tooth pulp amputations and root canal therapies were more frequent in patients aged below 12 years $(p<0.01)$ and permanent tooth root-canal therapies were more common in patients above 12 years old $(p<0.01)$. No statistical significance was found between age groups according to permanent tooth pulp amputations ( $p>0.01)$.

Table 6. Treatment modalities between age groups

\begin{tabular}{|c|c|c|c|c|}
\hline & \multicolumn{3}{|c|}{ Age group } & \multirow[t]{3}{*}{$\mathbf{P}$} \\
\hline & $\leq 12$ years & $>12$ years & Total & \\
\hline & Mean $\pm S D$ & Mean $\pm S D$ & Mean $\pm S D$ & \\
\hline $\begin{array}{l}\text { Decidous teeth pulp } \\
\text { capping }\end{array}$ & $5,55 \pm 3,54$ & $0,13 \pm 0,80$ & $4,84 \pm 3,79$ & $0,001 * *$ \\
\hline $\begin{array}{l}\text { Permanent tooth } \\
\text { pulp capping }\end{array}$ & $0,60 \pm 1,48$ & $4,55 \pm 3,31$ & $1,12 \pm 2,26$ & $0,001 * *$ \\
\hline $\begin{array}{l}\text { Decidous tooth } \\
\text { extraction }\end{array}$ & $0,10 \pm 0,71$ & $0,00 \pm 0,00$ & $0,09 \pm 0,66$ & 0,126 \\
\hline $\begin{array}{l}\text { Permanent tooth } \\
\text { extraction }\end{array}$ & $0,01 \pm 0,18$ & $0,03 \pm 0,23$ & $0,01 \pm 0,18$ & 0,126 \\
\hline Fissure restorations & $0,35 \pm 0,99$ & $0,04 \pm 0,25$ & $0,31 \pm 0,93$ & $0,004 * *$ \\
\hline $\begin{array}{l}\text { Amalgam } \\
\text { restorations }\end{array}$ & $0,04 \pm 0,29$ & $0,18 \pm 0,58$ & $0,06 \pm 0,35$ & $0,001 * *$ \\
\hline $\begin{array}{l}\text { Decidous tooth } \\
\text { amputation }\end{array}$ & $3,96 \pm 2,78$ & $0,00 \pm 0,00$ & $3,57 \pm 2,89$ & $0,001 * *$ \\
\hline $\begin{array}{l}\text { Permanent tooth } \\
\text { amputation }\end{array}$ & $0,03 \pm 0,29$ & $0,00 \pm 0,00$ & $0,03 \pm 0,27$ & 0,382 \\
\hline $\begin{array}{l}\text { Decidous tooth root- } \\
\text { canal therapy }\end{array}$ & $1,17 \pm 1,68$ & $0,05 \pm 0,29$ & $1,06 \pm 1,63$ & $0,001 * *$ \\
\hline $\begin{array}{l}\text { Permanent tooth } \\
\text { root-canal therapy }\end{array}$ & $0,45 \pm 1,16$ & $1,21 \pm 1,51$ & $0,52 \pm 1,21$ & $0,001 * *$ \\
\hline Root extraction & $0,05 \pm 0,32$ & $0,88 \pm 0,97$ & $0,13 \pm 0,5$ & $0,004 * *$ \\
\hline
\end{tabular}

Mann Whitney U Test

$* * p<0.01$

\section{DISCUSSION}

The study examined a considerable number of subjects (896) that a major percentage has undergone DGA $(79,4 \%)$. The percentage ranking of the evaluated patient group is as follows; anxiety $(46,5 \%)$, underaged child $(27,3 \%)$, patient with cooperation problems ( $14,1 \%)$, surgical necessity $(8,8 \%)$ and gagging reflex $(3,1 \%)$.

Evaluating dental anxiety, it can both occur in children and adults. Varience in percentage of populations may occur due to parent attitudes, population norms, dentist attitude and cooperation for explanation and social status (12-15).

Studies regarding patient demographics reveal that dental anxiety is higher in young females than males (16) and dental anxiety decreases with age (17). In this study, our demographics also revealed higher dental anxiety in females above 12 years age, in comparison to males. Coric et al (18) and Wu and Gao (19) also stated that dental enxiety and fear in children is with coexistence of the parents, family style and increases with child age.

Studies about DGA and CS of children have also been carried out. Tyrer, in his study suggested that the increased need for dental treatments in many sexants led to more referral for DGA in children. He also concluded younger age as a referral need (11). Our study data also includes that 245/ 600 child patients were underaged. Looking at the total number of patients, $27,3 \%$ were underaged children in this study. Richards et al (20) determined similar percentage of underaged childred $(30,7 \%)$ in his study that has evaluated 287 dental patients that has undergone GA in a 9 year period. Saxen et al (21) provided evidence that, due to widespread childhood caries, children having DGA had a peak below age 6 .

Evaluating the type of anesthesia, our study group revealed DGA rates $(79,4 \%)$ higher than CS $(20,6 \%)$ in all age groups. In regard to childrens' group, these rates are higher for DGA than CS $(98,1 \%$ to $1.9 \%)$. Whittle, in his study revealed that, the number of DGA's diminished $24 \%$, and the number of CS or inhalation anesthetics have increased slightly from $1997 / 98$ to $1999 / 2000$ (22). Regarding the time limitation, in contrast to DGA, CS may be handled better in patients having limited number of treatments to avoid more treatment sessions $(23,24)$.

\section{CONCLUSION}

The presented data here was collected from a single dental hospital that could manage daily hospitalization. Major maxillofacial surgeries in need of patient hospitalisation were not involved. This study indicates that a major percentage of all patients are formed by dental anxiety patients. As all patients were first evaluated for local anesthesia treatments, female patients older than 12 years tend to have higher and more persistent rate of dental anxiety.

\section{REFERENCES}

[1] Frassica JJ, Miller EC. Anesthesia management in pediatric and special needs patients undergoing dental and oral surgery. Int Anesthesiol Clin 1989;27(2):109-115.

[2] Lee PY, Chou MY, Chen YL, Chen LP, Wang CJ, Huang WH. Comprehensive dental treatment under general anesthesia in healthy and disabled children. Chang Gung Med J 2009;32(6):636-642.

[3] Nelson TM, Xu Z. Pediatric dental sedation: challenges and opportunities. Clin Cosmet Investig Dent 2015;7:97-106.

[4] Rosenberg J, Fuchs-Buder T. Why surgeons need to know about anaesthesia. Surg Endosc 2016 Sep;30(9):3661-3664.

[5] Nunn JH, Davidson G, Gordon PH, Storrs J. A retrospective review of a service to provide comprehensive dental care under general anesthesia. Spec Care Dentist 1995;15(3):97101.

[6] Bennett CR. Conscious sedation: an alternative to general anesthesia. J Dent Res 1984;63(6):832-833.

[7] Rosenberg MB, Campbell RL. Guidelines for intraoperative monitoring of dental patients undergoing conscious sedation, 
deep sedation, and general anesthesia. Oral Surg Oral Med Oral Pathol 1991;71(1):2-8.

[8] Rosenberg M; American Dental Association. New guidelines for the use and teaching of general anesthesia and sedation by dentists. J Mass Dent Soc 2010;58(4):22-27.

[9] Varpio M, Wellfelt B. Some characteristics of children with dental behaviour problems. Five-year follow-up of pedodontic treatment. Swed Dent J 1991;15(2):85-93.

[10] Craig DC, Wildsmith JA. Royal College of Anaesthetists; Royal College of Surgeons of England. Conscious sedation for dentistry: an update. Br Dent J 2007;203(11):629-631.

[11] Tyrer G L. Referrals for dental general anaesthetics - how many really need GA? Br Dent J 1999; 187: 440-443.

[12] Carter AE, Carter G, Boschen M, AlShwaimi E, George R. Pathways of fear and anxiety in dentistry: A review. World J Clin Cases. 2014;2(11):642-653.

[13] Storjord HP, Teodorsen MM, Bergdahl J, Wynn R, Kolset Johnsen JA. Dental anxiety: a comparison of students of dentistry, biology, and psychology. J Multidiscip Healthc 2014;7:413-418.

[14] Pop-Jordanova N, Sarakinova O, Markovska-Simoska S, Loleska S. Anxiety and personality characteristics in children undergoing dental interventions. Contributions. MASA (Sec Med Sci) 2013;34(3):93-103.

[15] Pop-Jordanova N, Sarakinova O, Pop-Stefanova-Trposka M, Zabokova-Bilbilova E, Kostadinovska E. Anxiety, Stress and Coping Patterns in Children in Dental Settings. Open Access Maced J Med Sci 2018;6(4):692-697.

[16] Pohjola V, Mattila A K, Joukamaa M, Lahti S. Anxiety and depressive disorders and dental fear among adults in Finland. Eur J Oral Sci 2011; 119: 55-60.
[17] Hill K B, Chadwick B, Freeman R, O’Sullivan I, Murray J J. Adult Dental Health Survey 2009: relationships between dental attendance patterns, oral health behaviour and the current barriers to dental care. Br Dent J 2013; 214: 25-32.

[18] Coric A, Banozic A, Klaric M, Vukojevic K, Puljak L. Dental fear and anxiety in older children: an association with parental dental anxiety and effective pain coping strategies. J Pain Res 2014;7:515-521.

[19] Wu L, Gao X. Children's dental fear and anxiety: exploring family related factors. BMC Oral Health 2018;18(1):100.

[20] Richards W, Razzaq K, Higgs G. An audit of dental general anaesthetic referral from a general dental practice in South Wales. Prim Dent Care 2009;16(4):143-147.

[21] Saxen MA, Urman RD, Yepes JF, Gabriel RA, Jones JE. Comparison of Anesthesia for Dental/ Oral Surgery by Officebased Dentist Anesthesiologists versus Operating Roombased Physician Anesthesiologists. Anesthesia Progress 2017;64(4):212-220.

[22] Whittle JG. The provision of primary care dental general anaesthesia and sedation in the north West region of England, 1996-1999. Br Dent J 2000; 189(9):500-502.

[23] Averley PA, Lane I, Sykes J, Girdler NM, Steen N, Bond S. An RCT pilot study to test the effects of intravenous midazolam as a conscious sedation technique for anxious children requiring dental treatment - an alternative to general anaesthesia. $\mathrm{Br}$ Dent J 2004;197(9):553-558.

[24] Lyratzopoulos G, Blain KM. Inhalation sedation with nitrous oxide as an alternative to dental general anaesthesia for children. J Public Health Med 2003;25(4):303-312. 